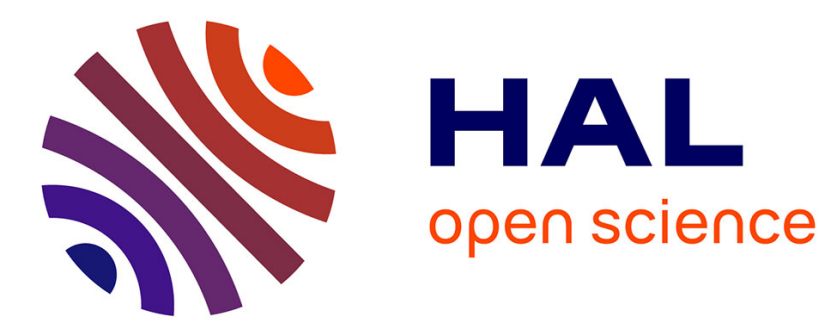

\title{
Threshold of Preference for Collusion and Interconnection Fees in Different Market Structures : the Tunisian Mobile Market Case
}

Sami Debbichi, Walid Hichri

\section{> To cite this version:}

Sami Debbichi, Walid Hichri. Threshold of Preference for Collusion and Interconnection Fees in Different Market Structures : the Tunisian Mobile Market Case. 2013. halshs-00794286

\section{HAL Id: halshs-00794286 \\ https://shs.hal.science/halshs-00794286}

Preprint submitted on 25 Feb 2013

HAL is a multi-disciplinary open access archive for the deposit and dissemination of scientific research documents, whether they are published or not. The documents may come from teaching and research institutions in France or abroad, or from public or private research centers.
L'archive ouverte pluridisciplinaire HAL, est destinée au dépôt et à la diffusion de documents scientifiques de niveau recherche, publiés ou non, émanant des établissements d'enseignement et de recherche français ou étrangers, des laboratoires publics ou privés. 
Threshold of Preference for Collusion and Interconnection Fees in Different Market Structures: the Tunisian Mobile Market Case

Sami Debbichi, Walid Hichri 


\section{GATE Groupe d'Analyse et de Théorie Économique Lyon-St Étienne}

93, chemin des Mouilles 69130 Ecully - France

Tel. +33(0)4 72866060

Fax $+33(0) 472866090$

6, rue Basse des Rives 42023 Saint-Etienne cedex 02 - France

Tel. +33 (0)4 77421960

Fax. +33 (0)4 77421950

Messagerie électronique / Email : gate@gate.cnrs.fr

Téléchargement / Download : http://www.gate.cnrs.fr - Publications / Working Papers 


\title{
Threshold of Preference for Collusion and Interconnection Fees in Different Market Structures: the Tunisian Mobile Market Case
}

\author{
Sami DEBBICHI *and Walid HICHRI ${ }^{\dagger}$
}

February 24th 2013

\begin{abstract}
We present a Cournot model that compares the critical threshold of collusion in Duopoly and Oligopoly Markets where the actors are private, mixed or public. We assume that the incentive critical threshold for collusion depends on the interconnection fees. The different threshold values calculated in each Market structure are then estimated, using the OLS method, with variables related to the Tunisian market structures and prices. The Econometric estimation of the different threshold values is consistent with our theoretical results. Our findings can be used by the decision makers to control collusion, by acting on the level of interconnection fees for each market structure and by implementing the suitable market liberalization policies in this sector.

Key Words: Interconnexion fees, Collusion, Market Structure, Private sector, Public Sctor, Tunisian Mobile Market.

JEL Classification: D47, L13, L51, L96
\end{abstract}

\section{Introduction:}

The mobile telephony market had known in the recent years a dynamic and changing structure in most of the countries who have undertaken to reform their telecommunications sectors. Depending on the characteristics of the local market (private or public sector) resulting from the restructuration and the implementation of progressive market liberalization policies, the number of actors (duopoly or oligopoly) and consequently their profits in the telecommunications industry has been variable. At the same time, some changing in the market structure was the result of a strategic behavior adopted by the several economic operators. In this context, collusion is one of the possibilities and strategies (Colombier et al. (2010)) that actors may adopt to control the market.

Laffont and Tirole (2000) present a study of competition in telecommunications, and a view of this competition from the United States was presented by Parsons (2002). In general, the Mobile telephony markets are either a duopoly, or an oligopoly, with a mix of private and public agents. They are facing an increasing number of customers. In such a context, there is no perfect competition and the telecommunications suppliers have generally the market under control. However, the decisions of the different actors directly influence each others, especially in presence of interconnection fees in the mobile telephony market.

*AEDD, University of Tunis El Manar

${ }^{\dagger}$ University of Lyon, F-69007, France; CNRS, GATE Lyon Saint Etienne, 93, Chemin de Mouilles, Ecully, F-69130, France; University Lyon 2, Lyon, F-69007, France; LAREQUAD; email: hichri@gate.cnrs.fr 
In fact, the Mobile telephony markets are originally a public monopoly, especially in the developing countries. The continuous and rapid changes in this sector oblige the decision makers to allow the entrance of private actors on the market, which suppose that the new entrants can have access to the existing network. Thus, this supposes a regulation of the interconnection fees that prevent the monopoly, while supplying interconnection services to new entrants, to charge high prices of interconnection that prevent the settlement of a real competition on the market (Girardi (2007), Abdel Jaoued (2001), Schiff (2005)). The interconnection fees have real economic issue and consequences, as shown in Baranes and Poudou (2010), Bulatovic (2004), Flochel (1999) and Baranes and Flochel (1999).

While the network interconnection prices are based upon costs in several developed countries (for example, this is the case in France), it is difficult to calculate and to provide interconnection services fairly and efficiently in the developing ones (Um et al. (2004)).

Several studies have already highlighted the determinants of the choice of colluding (Parker and Roller (1997) and Hoffler (2009)), and especially its relationship with the level of interconnection fees. In his study of this relationship among the suppliers of internet, Cortade (2005) shows that the preference for collusion does not depend on the level of the access fees, when the market structure is vertically separated. As shown in different applications in Penard (1997), collusion is a strategic behavior chosen by economic agents when the result is better in comparison with competition. Also, telecommunications networks may even use a high access charge as an instrument of collusion (Dessein(2003)).

We present in this paper a theoretical study of different market structures in presence of interconnection fees. We calculate the critical threshold of collusion, that is the level of interconnection fees from which the operators switch from/to collusion. The comparison of the different results permits to optimize and to control the degree of liberalization of the economy.

Our theoretical results are confronted with an econometric estimation of the threshold level of interconenction fees regarding to the decision of colluding. The data concerns the Tunisian mobile market. The choice of Tunisia, as a representative of the mobile phone market in most of the developing countries is due to the dynamic and important changes in this market during the last decade.

The market structure of the mobile phone in Tunisia has gone through several stages, from the monopolistic structure (1992-2001), to the duopolistic one (2002-2009) until reaching a three operators structure (from 2010 until today). In addition to the market structure, there has been changes in the market shares of the public and the private operators. Indeed, the privatization of Tunisia Telecom (T.T.) (the historical national operator) in 2006 transformed (theoretically) the market from a mixed (Private-Public) duopoly to a private one. With the entry of Orange Tunisia on the market in 2010, one should talk about a three private operators market. Obviously, the preference for collusion is certainly not the same in these different market structures.

The paper is organized as follows: Section 1 presents the theoretical framework in a Cournot competition market and specifies the strategic behavior of the operators according to the threshold of interconnection fees in a repeated game. We present thereafter, the interconnection fees in a duopoly (Section 2) and in an oligopoly (Section 3) market structure with private, mixed and public operators. We try to express the threshold of preference for collusion depending on the interconnection rate in these two scenarios, and to determine the optimal level for which the incentive to collude is higher. The different results obtained are discussed in Section 4.

Finally, the different threshold values calculated in each Market structure are estimated econometrically (Section 5) with the OLS method, using variables related to the Tunisian market structures and prices on 
this market.

\section{Theoretical Framework in a Duopoly Market}

Let's assume N operators on the Phone Market, who have the choice between colluding and competing. The incitation to collude will depend on the critical threshold of preference for collusion (C.T.P.C.) that is related to the discount factor $\delta$ of each operator.

Each operator has to choose between two strategic behaviors: either competing or colluding, regarding to the comparison between short-term gains to deviate and long-term losses after deviation, in a repeated game. In such a context, collusion is possible when the preference for the present, reflected by the discount rate $\mathrm{r}$ (with $\delta=\frac{1}{1+r}$ and $0 \leq \delta \leq 1$ ) is very low (Friedman (1971)).

Players are concerned with an indefinitely repeated sequential game where in the first stage, at period $t$ $=0$, they decide to collude. If they cooperate in period $\mathrm{t}=1$, player $\mathrm{i}$, where $i=\{1,2\}(N=2)$ realizes a profit equal to $\pi_{i}^{\text {Coll }}$. A unilateral deviation from collusion will change this profit to $\pi_{i}^{\text {Dev }}$, with $\pi_{i}^{\text {Dev }}>\pi_{i}^{\text {Coll }}$. We assume that a deviation of one player in period $t$ will be followed by a change in the cooperative behavior of the other operator in period $\mathrm{t}+1$ such that the profit of each operator becomes equal to $\pi_{i}^{\text {Comp }}$, as both operators deviate from collusion.

Calculations of the updated value of profit after Deviation $V^{\text {Dev }}$ and the updated value of profit after Collusion $V^{\text {Coll }}$ show that:

$$
V^{D e v}=\sum_{t=1}^{\infty} \delta^{t} \pi_{i}^{C o m p}=\frac{\delta}{1-\delta} \pi_{i}^{C o m p}
$$

and

$$
V^{\text {Coll }}=\sum_{t=1}^{\infty} \delta^{t} \pi_{i}^{\text {Coll }}=\frac{\delta}{1-\delta} \pi^{\text {Coll }}
$$

Collusion is a better strategy if the profit resulting from Deviation, in a repeated game, is lower than the difference between the updated value of profit after Collusion and the updated value of profit after Deviation:

$$
\frac{\delta}{1-\delta}\left(\pi_{i}^{\text {Coll }}-\pi_{i}^{C o m p}\right)>\pi_{i}^{\text {Dev }}-\pi_{i}^{\text {Coll }}
$$

From this inequality, we can calculate the threshold of the discount factor $\bar{\delta}$ from which collusion becomes possible:

$$
\delta>\bar{\delta}=\frac{\pi_{i}^{D e v}-\pi_{i}^{C o l l}}{\pi_{i}^{D e v}-\pi_{i}^{C o m p}}
$$

Consequently, if the value of $\delta$ for one operator is higher than $\bar{\delta}$, collusion will be the best strategy to choose. We will discuss next the variation of $\bar{\delta}$ when the interconnection fees $a$ vary to see, for each value of $a$, the variation of the critical threshold of preference for collusion (C.T.P.C.).

\subsection{A Duopoly Market with Private operators:}

We assume that the number of operators is equal to two $(N=2)$, and that, in absence of a public operator, each agent will try to maximize his profit. We assume that they compete in a Cournot Market. The profit 
function of one operator $i \neq j$ where $\mathrm{i}$ and $\mathrm{j} \in\{1,2\}$, in presence of interconnexion fees $a$, is equal to:

$$
\pi_{i}=\left(P_{i}(Q)-a\right) \cdot q_{i j}+a \cdot q_{j i}
$$

where $P_{i}(Q)=P_{j}(Q)=1-Q$ is the price function and $Q=q_{i j}+q_{j i}$ is the total quantity of interconnection produced by both operators. The resulting reaction function of player $\mathrm{i}$ is equal to:

$$
q_{i j}\left(q_{j i}\right)=\frac{1-q_{j i}-a}{2}
$$

In such a contex, the optimal quantity to be produced by operators $i$ and $j$ is:

$$
q_{i j}^{*}=q_{j i}^{*}=\frac{1-a}{3}
$$

and the resulting profit is:

$$
\pi_{i}^{*}=\pi_{j}^{*}=\frac{(1+2 a) \cdot(1-a)}{9}
$$

If both operators decide to collude with equal sharing of profits, the joint profit $\pi_{J}$ can be written as follows:

$$
\pi_{J}=(P(Q)-a) \cdot Q+a \cdot Q=(1-Q) \cdot Q
$$

Maximizing this joint profit gives us a total quantity produced $Q_{J}^{*}$ equal to $1 / 2$ and a total joint profit $\pi_{J}$ equal to $1 / 4$, which corresponds, with the equal sharing rule, to a quantity per operator $q_{i j}^{\text {Coll }}=q_{j i}^{\text {Coll }}$ equal to $1 / 4$ and a profit of collusion $\pi_{i}^{\text {Coll }}=\pi_{j}^{\text {Coll }}$ equal to $1 / 8$.

Suppose that one of the two operators (player $i$ ) chooses to deviate from the collusive agreement. In this case, it is assumed that his rival keeps constant his output level (1/4) after the collusion strategy. The quantity produced by player $i$ with defection is:

$$
q_{i j}^{D e v}=\frac{1}{2} \cdot\left(\frac{3}{4}-a\right)
$$

The profit of player $i$ resulting from deviation is then:

$$
\pi_{i j}^{D e v}=\left(1-q_{i j}^{D e v}-q_{i j}^{C o l l}-a\right) \cdot q_{i j}^{D e v}+a q_{j i}^{C o l l}
$$

Calculations show that

$$
\pi_{i j}^{D e v}=\pi_{j i}^{D e v}=\frac{9}{64}+\frac{1}{4} a\left(a-\frac{1}{2}\right)
$$

Using the equation calculated previously, the threshold discount factors $\bar{\delta}$, above which collusive agreement is sustainable, is the same for both players and is equal to:

$$
\bar{\delta}=\frac{\frac{1}{64}+\frac{1}{4} a\left(a-\frac{1}{2}\right)}{\frac{9}{64}+\frac{1}{4} a\left(a-\frac{1}{2}\right)-\frac{1}{9}(1+2 a)(1-a)}=\frac{9}{17}
$$

This result shows that, in a private duopoly in presence of Cournot competition, the critical threshold of 
preference for collusion (C.T.P.C) $\bar{\delta}$ is constant. Thus, the preference for collusion doesn't depend in such a market structure on the value of interconnection fees $a$.

\subsection{A Duopoly Market with Mixed operators:}

In presence of two operators of different natures, while the private one (player $i$ ) continue the maximization of his profit $\pi_{i}$, we assume that the public operator (player $j$ ) maximizes the collective profit $\tilde{\pi_{j}}$, representing the sum of the consumers' surplus and $\pi_{i}$ :

$$
\begin{aligned}
& \pi_{i}=\left(1-q_{i j}-q_{j i}-a\right) \cdot q_{i j}+a q_{j i} \\
& \tilde{\pi}_{j}=\int_{0}^{Q} P(Q) d Q-P(Q) \cdot Q+\pi_{i}=\frac{1}{2}\left(q_{i j}+q_{j i}\right)^{2}+\left(1-q_{i j}-q_{j i}-a\right) \cdot q_{i j}+a q_{j i}
\end{aligned}
$$

The quantities at the equilibrium for both players are $q_{j i}^{*}=(1-a)$ for the public operator and $q_{i j}^{*}=0$ for the private one. The resulting profits are respectively $\pi_{i}^{*}=a(1-a)$ and $\tilde{\pi}_{j}^{*}=\frac{1}{2}(1-a)^{2}$. Consequently, the private operator will not produce and has a positive profit resulting from the presence of externalities and interconnection fees of the public operator.

The comparison between both profits shows that $\pi_{i}^{*}>\tilde{\pi}_{j}^{*}$ if the interconnection fees $a>\frac{1}{3}$.

If both operators decide to collude, they will maximize their joint profit $\pi_{J}$, where:

$$
\pi_{J}=\frac{1}{2} Q^{2}+(1-Q-a) Q+a Q
$$

The solutions of this program are $Q_{J}^{*}=1$ and $\pi_{J}^{*}=\frac{1}{2}$. An equal sharing of the market and profits gives then for each operator an interconnection quantity equal to $\frac{1}{2}$ and a profit equal to $\frac{1}{4}$.

Suppose that the private operator (player $i$ ) deviates from collusion and maximizes his own profit $\pi_{i}^{\text {Dev }}$, while the public operator still continue cooperating. In such a context, the public operator will continue producing a quantity $q_{j i}^{J}$ equal to $\frac{1}{2}$ and the private operator will produce a quantity $q_{i j}^{D e v}$ equal to $\frac{1}{2}\left(\frac{1}{2}-a\right)$ and will generate a profit $\pi_{i}^{D e v}=\frac{1}{4} a(a+1)+\frac{1}{16}$. The critical threshold of preference for collusion (C.T.P.C.) $\bar{\delta}$ is then equal to:

$$
\bar{\delta}=\frac{a^{2}+a-\frac{3}{4}}{5 a^{2}-3 a+\frac{1}{4}}
$$

This threshold vary with interconnection fees, and if the discount factor of one operator is higher that $\bar{\delta}$, then collusion is the best strategy.

\subsection{A Duopoly Market with Public operators:}

Although this case is not realistic, as we rarely find sectors with two public agents, it remains interesting to compare the results of this market configuration with the two previous cases.

With two public operators, where each agent maximizes the collective surplus, each one produces a quantity equal to $(1-a)$, and makes a profit equal to $(1-a)$. If both operators collude and share equally the market, each one will produce a quantity equal to $\frac{1}{2}$ and will make a profit equal to $\frac{1}{4}$. However, if one of them deviates, he will produce a quantity equal to $(1-a)$, which allows him with a profit equal to $\frac{1}{2} a^{2}-\frac{1}{2} a+\frac{5}{8}$. In this case, the critical threshold of preference for collusion is: 


$$
\bar{\delta}=\frac{a^{2}+-a+\frac{3}{4}}{a^{2}+a-\frac{3}{4}}
$$

As in the previous market structure, The threshold vary with interconnection fees, and the operator will collude if his discount factor $\delta$ is higher that $\bar{\delta}$.

\section{Theoretical Framework with three operators:}

Assuming that the number of operators on the market is equal to three $(N=3)$, we'll present successively different market structures where the number of private operators varies from three to zero.

\subsection{An oligopoly Market with three private operators:}

We'll suppose in this section that there are three operators $i, j$ and $k$, where $i, j$ and $k \in\{1,2,3\}$ and $i \neq j \neq k$. The profit of operator $i$ depends on the quantity $q_{i j}$ he puts in competition with operator $j$, but also on the quantity $q_{i k}$ he puts in competition with operator $k$. The total quantity produced by the operator $i$ is $q_{i}=q_{i j}+q_{i k}$. The total quantity available on the market is $Q=q_{i}+q_{j}+q_{k}$.

Each operator tries to maximize his profit. The profit of operator $i$ is:

$$
\pi_{i}=\left(P_{i}(Q)-a\right)\left(q_{i j}+q_{i k}\right)+a\left(q_{j i}+q_{k i}\right)
$$

With a price function $P(Q)=1-Q$, maximizing the profit of each operator regarding to the total optimal quantity he puts on the market, shows that $q_{i}=q_{j}=q_{k}=\frac{1-a}{4}$. These quantities allow each operator with a same profit equal to $\frac{(1+a) \cdot(1-3 a)}{16}$.

If the three operators decide to collude, they will realize a joint profit equal to $\frac{3}{4}$, which corresponds to an individual profit $\pi_{i}^{\text {Coll }}$ equal to $\frac{1}{4}$ and to a same share of production equal to $\frac{1}{6}$ for each operator.

To study the effect of deviation from collusion, suppose that agent $i$ deviates and maximizes his own profit $\pi_{i}^{D e v}$, and let's assume that agents $j$ and $k$ maintain their cooperative behavior. Such a behavior will permit player $i$ to realize a profit $\pi_{i}^{\text {Dev }}$ equal to $\frac{3}{4} a^{2}-\frac{1}{6} a+\frac{1}{9}$.

In this case, the threshold of the discount factor $\bar{\delta}$ is equal to:

$$
\bar{\delta}=\frac{\frac{3}{4} a^{2}-\frac{2}{3} a-\frac{3}{54}}{\frac{3}{4} a^{2}-\frac{2}{3} a+\frac{1}{9}-\frac{1}{16}(1-a)(1-3 a)}
$$

This threshold, above which collusion is preferred to deviation, is still calculated as in the duopoly case and varies with interconnection fees $a$.

\subsection{A mixed oligopoly Market with one public and two private operators:}

A mixed oligopoly is a particular market structure where the private and public operators do not have the same characteristics. The differences can concern the technology used by each operator (Ouatara (2011)). But even when these different operators have the same technology, the possibility of merging may be possible only under some restrictions (Artz et al (2009)). 
Let's assume now that the market is composed of one public and two private operators (see De Donder (2005) for an example of competition of a public firm in a mixed oligopoly). In such a context, the private agents $i$ and $j$ will continue maximizing their own profits, while the public operator $k$ will maximize the total surplus. The two profits and the surplus function are respectively as follows:

$$
\begin{gathered}
\pi_{i}=\left(1-\left(q_{i j}+q_{i k}\right)-\left(q_{j i}+q_{j k}\right)-\left(q_{k i}+q_{k j}\right)-a\right) \cdot\left(q_{i j}+q_{i k}\right)+a q_{j i}+a q_{k i} \\
\pi_{j}=\left(1-\left(q_{i j}+q_{i k}\right)-\left(q_{j i}+q_{j k}\right)-\left(q_{k i}+q_{k j}\right)-a\right) \cdot\left(q_{j i}+q_{j k}\right)+a q_{i j}+a q_{k j} \\
\tilde{\pi_{k}}=\frac{1}{2}\left(q_{k i}+q_{k j}+q_{j i}+q_{j k}+q_{i j}+q_{i k}\right)^{2}+\left(1-q_{k i}-q_{k j}-q_{j i}-q_{j k}-q_{i j}-q_{i k}-a\right) \cdot\left(q_{k i}+q_{k j}\right)+a q_{j k}+a q_{i k}
\end{gathered}
$$

We still assume that the demand function is $P(Q)=1-Q$. Operator $i$ will maximize his profit regarding the total quantity $\left(q_{i j}+q_{i k}\right)$ of calls on the network. The two other operators will behave in a symmetric way. Consequently, the first order conditions obtained from the resolution of the previous equations show that $\left(q_{i j}^{*}+q_{i k}^{*}\right)=\left(q_{j i}^{*}+q_{j k}^{*}\right)=0$ and $\left(q_{k i}^{*}+q_{k j}^{*}\right)=(1-a)$.

As a result, the private operators $i$ and $j$ realize the same profit (respectively $\pi_{i}^{*}$ and $\pi_{j}^{*}$ ) equal to $\frac{a(1-a)}{2}$. However, the public operator will realize a profit $\pi_{k}^{*}$ equal to $\frac{(1-a)^{2}}{2}$.

This means that the private operators will not produce strategically any quantities, and in presence of externalities, they will realize a positive profit.

In the case where the three operators decide to collude, they will behave as a monopoly, and maximize their joint profit $\pi_{J}$, where:

$$
\pi_{J}=\frac{1}{2} Q^{2}+(1-Q-a) Q+a Q
$$

The optimal quantities produced in such a context are such that the total quantity of interconnection produced by the three operators is $Q^{\text {Coll }}=1$, which corresponds to an equal share of the market corresponding to $\frac{1}{3}$ for each operator. Consequently, the total profit resulting from collusion is equal to $\frac{1}{2}$, and the individual profit for each operator is equal to $\frac{1}{6}$.

To understand the consequences of deviation in an oligopoly market with one public and two private operators, we'll assume that one of the two private agents, say operator $i$, deviates from the situation of collusion. This assumption is more close to reality, as the public operator maximizes the total surplus, and doesn't have the willingness to make profits.

By choosing collusion, operator $i$ maximizes his profit $\pi_{i}^{D e v}$ while assuming that the two other operators will not change their strategies on the market and will continue looking for collusion by producing quantities equal to $\frac{1}{3}$ for each operator. Meanwhile, the private operator looking for deviation will produce a quantity $\left(q_{i j}^{D e v}+q_{i k}^{D e v}\right)=\frac{1}{2}\left(\frac{1}{3}-a\right)$ and will generate a profit $\pi_{i}^{D e v}=\frac{1}{4} a^{2}+\frac{1}{6} a+\frac{1}{36}$. The critical threshold of preference for collusion (C.T.P.C.) $\bar{\delta}$ is then equal to:

$$
\bar{\delta}=\frac{3 a^{2}+2 a-\frac{5}{3}}{9 a^{2}-4 a+\frac{1}{3}}
$$

This threshold still depends on interconnection fees $a$. 


\subsection{A mixed oligopoly Market with one private and two public and operators:}

This market structure with one private and two public operators is not realistic, as it is difficult to find in the same market two public agents. Nevertheless, this can be the case when collusion concerns different countries that are trying to merge their economies, or some regions of the world that are trying to set up a political or economic union.

Our model shows that in the case where there are two public operators, in presence of only one private operator, the critical threshold of preference for collusion (C.T.P.C.) remains the same than the one found in the previous case. Thus, we find that in a mixed market structure with three operators, the number of private or public operators has no effect on the preferences for collusion.

\subsection{An oligopoly Market with three public operators:}

Although the case of a market with three public operators, as in the previous market structure, can be studied only in very specific and transitional situations, the comparison with the other market structures still remains very interesting.

If each public operator maximizes the total surplus, the resulting optimal quantities produced by each one is equal to $\frac{(1-a)}{3}$ and the individual profits are the same and equal to $\frac{-5}{18} a^{2}+\frac{2}{9} a+\frac{1}{18}$. However, the strategy of collusion allows each operator to produce a quantity equal to $\frac{1}{6}$ and to make a profit equal to $\frac{1}{6}$.

If one of the three public operators, say operator $i$, deviates from collusion, the optimal total quantity he should produce is equal to $\left(\frac{1}{3}-a\right)$, consequently to the maximization of his profit:

$\pi_{i}^{D e v}=\frac{1}{2}\left(q_{i j}^{D e v}+q_{i k}^{D e v}\right)^{2}+\left(1-\left(q_{i j}^{D e v}+q_{i k}^{D e v}\right)-\left(q_{j i}^{\text {Coll }}+q_{j k}^{\text {Coll }}\right)-\left(q_{k i}^{\text {Coll }}+q_{k j}^{\text {Coll }}\right)-a\right)\left(q_{i j}^{\text {Dev }}+q_{i k}^{D e v}\right)+a\left(q_{j i}^{\text {Coll }}+q_{k i}^{\text {Coll }}\right)$

The maximized profit is equal to $\pi_{i}^{D e v}=\frac{1}{2} a^{2}+\frac{1}{18}$. Thus, the critical threshold of preference for collusion $\bar{\delta}$ is equal to $\frac{9 a^{2}-2}{12 a^{2}-4 a}$.

We present in section 4 a discussion of the relationship between the critical threshold of preference for collusion (C.T.P.C.) and interconnection fees $a$ in all the market structures presented previously.

\section{Results and Discussion}

Our results show that the critical threshold of preference for collusion (C.T.P.C.) depends on the interconnection fees $a$ when the market structure is composed of three operators, regardless of whether the operators were private or public. This is also the case in presence of only two operators, except when both operators are private.

As shown in the following figures, the critical threshold of preference for collusion function is decreasing and convex in a duopoly (see Figure 1). 

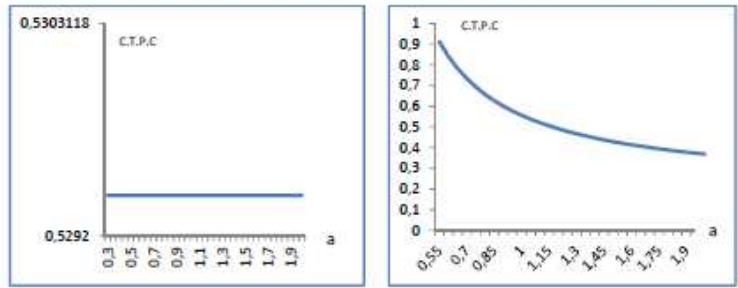

Two Private Operators

One Private and One Public Operators

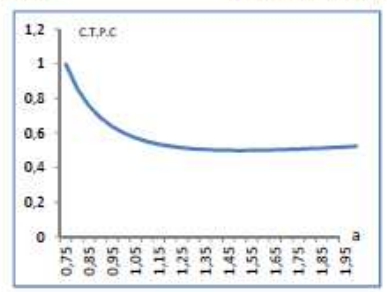

Two Poblic Operators

Figure 1 : Variation of the Critical Threshold of Preference for Collusion (C.T.P.C.) with Interconnection Fees $a$ in a Duopoly Market Structure.

The critical threshold of preference for collusion (C.T.P.C.) becomes increasing and concave, at least for certain values of interconnection fees $a$, in presence of three operators (see Figure 2).

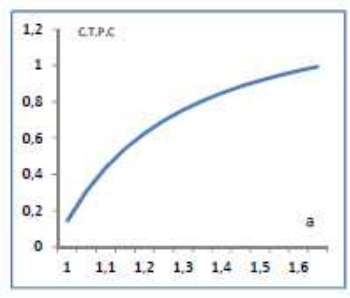

Three Private Operators

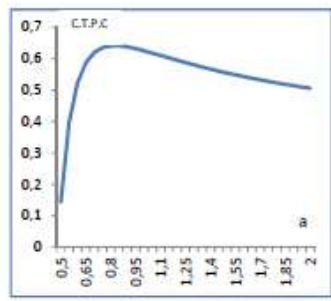

Three Mined (Two Private and one Public)

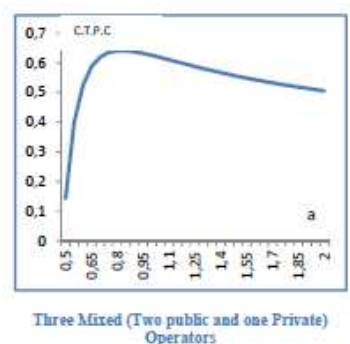

Operators

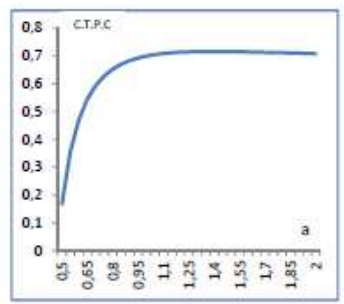

Three Public Operators

Figure 2 : Variation of the Critical Threshold of Preference for Collusion (C.T.P.C.) with Interconnection Fees $a$ in Presence of Three Operators on the Market.

Consequently, the relationship between this threshold and interconnection fees $a$ is changing and varies with market structure.

In fact, as $\bar{\delta}$ is equal to:

$$
\bar{\delta}=\frac{\pi_{i}^{D e v}-\pi_{i}^{C o l l}}{\pi_{i}^{D e v}-\pi_{i}^{C o m p}}=\frac{F(a)}{G(a)}
$$

if the value of $\delta$ for one operator is higher than $\bar{\delta}$, collusion will be the best strategy to choose. This is the case for all the points that are above the curves represented in Figures 1 and 2. According to these figures, 
in a duopoly market, as interconnection fees $a$ increase, it becomes easier for the operators to collude, except for the two private operators case where the critical threshold of preference for collusion (C.T.P.C.) do not vary with interconnection fees. However, for the same variation of interconnection fees, collusion becomes more difficult to realize in presence of three operators.

While the critical threshold of preference for collusion (C.T.P.C.) never reaches its minimum possible value in the three cases of the duopoly market structure, this Critical Threshold of Preference for Collusion (C.T.P.C.), in a three operators purely public and mixed markets, never reaches the maximum value equal to one. It reaches such a value only in the case of a purely private market structure with three operators, when interconnection fees increase to 1.6 (see Figure 2).

The concavity of the increasing function of $\bar{\delta}$ in a three operators market means that, as interconnection fees increase, the interest to deviate from collusion ( $\mathrm{F}(\mathrm{a})$ ) increases less in comparison to the increase of the interest to deviate from competition (G(a)). It becomes then more and more difficult to collude.

Figure 2 shows also that, when interconnection fees value $a$ is low (lower than 1.2), collusion is more easy to realize in a market structure with three private operators. However, for higher values of $a$, collusion becomes more difficult in this market structure than in the three other cases with three operators.

\section{Econometric estimation of the critical threshold of preference for collusion in the Tunisian phone market}

The Tunisian mobile market structure was historically an public monopoly with one operator (Tunisia Telecom (T.T.)). Since 2002, a private operator (Tunisiana) has entered on the market. In 2006, the public operator (Tunisia Telecom (T.T.)) becomes a private one. Finally, in 2010, a third private operator (Orange Tunisia) joined the market to transform the duopoly private structure into a three private operators market. As mentioned in Debbichi and Ben Khalifa (2013), "one of the major inefficiencies of competition on mobile phone market in Tunisia is that the evolution of interconnection rates have witnessed a low decrease after the year 2008, but some stability between years 2003 and 2008, in the duopoly period." Using these calculated interconnection rates, and the calculations made above for the critical threshold of preference for collusion (C.T.P.C.), we are able to calculate the variation of this threshold from 2003 to 2011 on the Tunisian phone market. The results are presented in Figure 3.

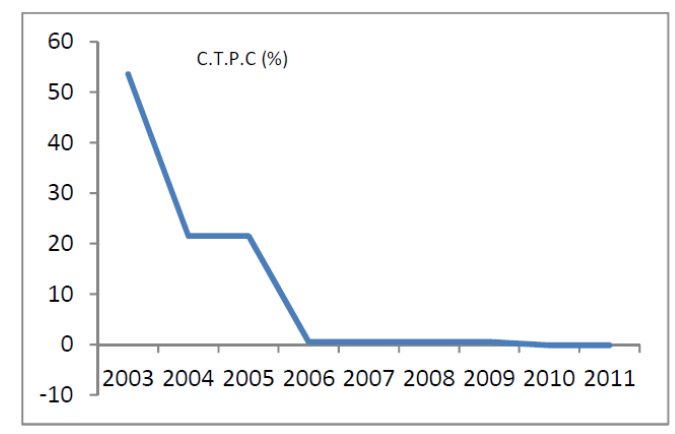

Figure 3: Evolution of the Critical Threshold of Preference for Collusion in the Tunisian Mobile Market from 2003 to 2011.

As shown in Figure 3, the values of the critical threshold of preference for collusion (C.T.P.C) were high during the period 2003-2005. The curve of this threshold $\delta$ is decreasing and convex and reaches the zero 
value in 2006, when the public operator (Tunisia Telecom (T.T.)) becomes private. This threshold becomes negative in 2010, the date that corresponds to the entry of the third operator (Orange Tunisia) on the market. In the Tunisian mobile market, we have then since 2010:

$$
\pi_{i}^{\text {Comp }}<\pi_{i}^{\text {Dev }}<\pi_{i}^{\text {Coll }}
$$

This result is logical since a decrease in the wholesale price leads to a decrease in the margin between the retail price paid by the consumer and the interconnection rate exchanged. This encourages cartel members to prefer not to deviate from the collusive agreement, and as a consequence, the critical threshold of preference for collusion $\delta$ decreases.

On the other hand, another explanation can be found in the fact that the market for mobile telephony in Tunisia was experiencing strong growth in demand during the period 2003-2005, which leads the two operators to have a very high discount rate, and consequently, a strong preference for the future and therefore a preference for collusion.

We'll test econometrically the assumption (Penard (2003)) according to which any factor that increases competition between operators is more promising incentive for collusion. We will then express the effect of each retained variable on the critical threshold of preference for collusion (C.T.P.C.).

The variables of the estimated model are of two kinds. Either they are related to the market structure, or they concern the prices on the Tunisian mobile market. The first type of variables includes competition (COMP), measured by the number of mobile operators who have installed their networks and who are marketing their services. In fact, there is a relationship between the number of competitors and collusion, as shown in Selten (1973) who presents a theory that investigates "the connection between the number of competitors and the tendency to cooperate." The importance of the number of competitors as a variable is at the origin of the distinction made by Chamberlin (1933) between small group and the large group.

The first type of variables includes also a measure of market concentration (HHI), Expressed by the HHI index. This index is established by summing the squared market shares (usually multiplied by 100) of all the operators. The more the HHI index is high, the more the market is concentrated and the more preference for collusion is strong.

The two other variables of the first kind are market shares convergence (CONV) measured by the difference between the market shares of operators expressed in percentage (the more market shares are converging (difference tends to zero), the more collusion is easy) and the Lerner index (LI), as presented in Debbichi and Ben Khalifa (2013). This index reflects the degree of market power for operators. The more the price is far from the marginal cost, the more the market power is important, and the more preference for collusion is strong. This variable is constructed on the assumption called "Balanced Calling Pattern" (Laffont and Tirole (2000)) and according to which, the fraction of calls from the original network and ending on the other competing network is proportional to the market share of the competitor. In other words, the flows of incoming and outgoing calls are balanced, even if market shares are not.

The second type of variables includes the retail prices (RP) and the wholesale ones (WP). The retail prices represent off-net prices charged by operators expressed in local Tunisian currency without taking into account taxes, and paid by the consumer. If the price increases, the margin between the retail price and the wholesale price increases and hence the preference for collusion increases. The whole sale prices represent the interconnection rates charged and exchanged between operators expressed in Tunisian local currency without taxes. If this rate increases, the margin between the retail price and the tariff decreases and hence preference for collusion decreases. 
All variables of the estimated model are expressed in logarithms and are estimated by the method of Ordinary Least Squares (OLS) for the period 2002-2011. The results are given in the following table (Table 1).

\begin{tabular}{lllll} 
Variables & Coefficient & Std. Error & t-Statistic & Prob. \\
\hline \hline & & & & \\
C & -8.538721 & 1.760182 & -4.851045 & 0.0167 \\
LOG $($ HHI) & 2.648236 & 0.596195 & 4.441894 & 0.0212 \\
LOG(LI) & 0.304238 & 0.083714 & 3.634236 & 0.0359 \\
LOG(RP) & 0.122151 & 0.110119 & 1.109267 & 0.3482 \\
LOG(WP) & -4.172169 & 0.825320 & -5.055214 & 0.0149 \\
LOG(CONV) & -0.803487 & 0.084987 & -9.454268 & 0.0025 \\
LOG(COMP) & 2.072900 & 0.690068 & 3.003908 & 0.0575 \\
\hline \hline & & & \\
R-squared & 0.983776 & Mean dependent var & 0.589970 \\
Adjusted $R$-squared & 0.951327 & S.D. dependent var & 0.796558 \\
S.E. of regression & 0.175736 & Akaike info criterion & -0.443644 \\
Sum squared resid & 0.092649 & Schwarz criterion & -0.231835 \\
Log likelihood & 9.218222 & F-statistic & 30.31816 \\
Durbin-Watson stat & 2.884862 & Prob (F-statistic) & 0.008866 \\
\hline \hline
\end{tabular}

Table 1: Estimation of the critical threshold of preference for collusion (C.T.P.C.) with OLS

As shown in Table 1, all variables are significant at the level of $1 \%$. Variables associated with the convergence of market shares (CONV) and with the wholesale prices (WP) seem to have a negative coefficient. This means that an increase in one of these variables will decrease the critical threshold of preference for collusion (C.T.P.C.) and will make it for the operators easier to collude. All the other variables are positively correlated with the critical threshold of preference for collusion (C.T.P.C.).

\section{Conclusion:}

The model we present above determines the critical threshold of preference for collusion (C.T.P.C.) depending on the market structure and the nature (private or public) of the operators that are present on the market. This threshold is a relevant indicator available for the regulator to estimate the preferences of the operators to collude. To keep a certain degree of competition, the regulator, as in Flacher and Jennequin (2007), can set the level of interconnection rate at a level that minimizes the preference for collusion. Our study shows also that the critical incentive to collude depends on the level of interconnection fees. When these fees vary, the curve of the critical threshold of preference for collusion (C.T.P.C.) is generally convex in a duopoly structure, and becomes concave in presence of three operators. We have shown also that, in a duopoly structure, collusion becomes easier when interconnection fees increase, whereas in a market with three operators, collusion becomes more difficult when interconnection fees are more important. Using the different calculated values of the critical threshold of preference for collusion (C.T.P.C.), and regarding the changes in structures observed on the Tunisian telecommunication market, we find that this estimated threshold is decreasing and convex in time on the Tunisian market during the period 2003-2011, until reaching negative values in 2010. This proves that there is a strong preference for collusion between the Tunisian telephony mobile operators. This preference has increased with the privatization of the public operator that took place in 2006 and with the increase of the number of operators in 2010. Finally, we find that, while studying the 
effect of the public-private nature of operators, the number of operators, and hence the market structure is more important than the nature of the operators for the determination of the critical threshold of preference for collusion.

\section{References}

[1] Abdel Jaoued, A.: "L’interconnexion aux Réseaux de Télécommunications : L'émergence dun nouveau droit," R.J.L, (2001).

[2] Artz B., Heywood, J. and McGinty, M.: "The merger paradox in a mixed oligopoly," Research in Economics, 63,1-10, (2009).

[3] Baranes, E. and Flochel, L.: "Interconnexion de réseaux et qualité de l'infrastructure comme barrière à lentrée : Quels Instruments de Régulation," Recherches Economiques de Louvain 65(1), (1999).

[4] Baranes, E. and Poudou, J.C.: "Cost-based access regulation and collusion in a differentiated duopoly," Economics Letters, 106, 172176, (2010).

[5] Bulatovic, V.: "Les Enjeux Economiques de l'Interconnexion des Réseaux de Télécommunications," Thesis (PhD in Economics), University Of Orleans, (2004).

[6] Chamberlin, E.H.: "The Theory of Monopolistic Competition," Cambridge. Mass. (1933).

[7] Colombier, N., M'Chirgui, Z. and Pénard, T.: "Une analyse empirique des stratégies d'interconnexion des opérateurs internet," Journal déconomie industrielle, No 131, pp. 25-50, (2010).

[8] Cortade, T.: "Règlementation, Structures de Marché et Comportements Stratégique Sur le Marché de l'Internet," Thesis (PhD in Economics), University of Montpellier, (2005).

[9] De Donder, P.: "L'entreprise publique en concurrence : les oligopoles mixtes," Revue française d'économie. Volume 20 No 2, 2005. pp. 11-50, (2005).

[10] Debbichi, S. and Ben Khalifa, A.: "Market conduct, interconnection costs and benchmarking in mobile phone industry: the Tunisian case," Int. J. Mobile Learning and Organisation, Vol. 7, No. 1, (2013)

[11] Dessein, W.: "Networkcompetition in nonlinear pricing," RAND Journal of Economics, Vol. 34, No 4, pp. 593-611, (2003).

[12] Flacher, D., and Jennequin, H.: "Réguler le secteur des Télécommunications ? Enjeux et perspectives," ed. Economica, (2007).

[13] Flochel, L.: "Interconnexion de Réseaux et Charges daccès : Une Analyse stratégique," Annales d'économie et de statistique, No 53, (1999).

[14] Friedman, J.: "A non-cooperative equilibrium for supergames", Review of Economic Studies 38 (1): 1-12, (1971).

[15] Girardi, B.: "L'utilisation de la comptabilité de gestion dans la régulation : le cas de la régulation de l'interconnexion dans les télécommunications en France", (2007). 
[16] Hoffler, F.: "Mobile Termination and collusion, Revisted," Journal of Regulatory Economics, vol. 35, pp. 246-274, (2009).

[17] Laffont, J.-J. and Tirole, J.: "Competition in Telecommunications." Cambridge, Mass.: MIT Press, (2000).

[18] Ouattara, S.K.: "Profitabilité des fusions dans un oligopole mixte asymétrique," Working Paper CREM, No 26, (2011).

[19] Parker, P.M. and Roller, L.H.: "Collusive conduct in duopolies: multimarket contact and cross-ownership in the mobile telephone industry," RAND Journal of Economics Vol. 28, No. 2, pp. 304-322, (1997).

[20] Parsons, S.G.: "Laffont and Tirole's Competition in Telecommunications: a view from the US," International Journal of the Economics of Business, Vol.9, Nř3, pp. 419-436, (2002).

[21] Pénard, T.: "Collusion et Comportement dynamiques en oligopole : une synthèse," working paper CREREG, University of Rennes 1, (1997).

[22] Pénard, T.: "Structures du marché et pratiques facilitant la collusion : une approche par la théorie des jeux répétés," Économie rurale, Vol. 277, No 277-278, pp. 80-98, (2003)

[23] Schiff, A.F.: "Three Essays in Network Economics: Two-Way Interconnection, Two-Sided Networks, and Reputation Systems," Thesis (PhD in Economics), University of Auckland, (2005).

[24] Selten, R.: "A simple model of imperfect competition, where 4 are few and 6 are many," International Journal of Game Theory, Volume 2, Issue 1, pp 141-201, (1973). 